M. H. NGUYEN, K. T. O'BRIEN, A. B. SMITH, III* (UNIVERSITY OF PENNSYLVANIA, PHILADELPHIA, USA)

Design, Synthesis, and Application of Polymer-Supported Silicon-Transfer Agents for Cross-Coupling Reactions with Organolithium Reagents

J. Org. Chem. 2017, 82, 11056-11071.

\section{Pd-Catalyzed Cross-Coupling Mediated by Polymer-Supported Siloxanes}

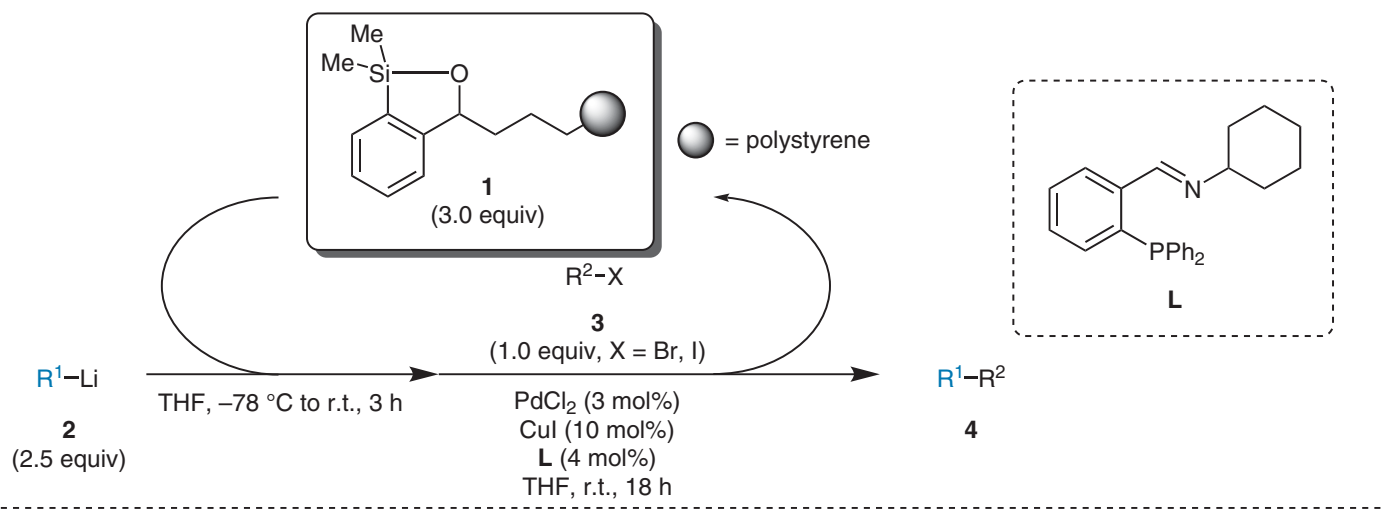

\section{Gategory}

Polymer-Supported

Synthesis

Key words

\section{silicon}

organolithium reagents

palladium catalysis

cross-coupling

transfer agents

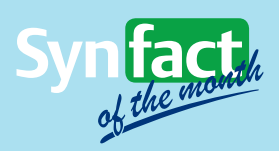<smiles>COc1ccc(-c2ccc(C(C)(C)C)cc2)cc1</smiles>

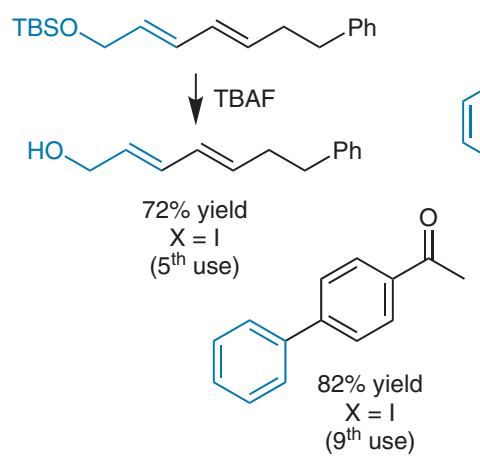<smiles>N#Cc1ccc(-c2ccccc2)cc1</smiles>
$92 \%$ yield $\mathrm{X}=\mathrm{I}$ (6 $6^{\text {th }}$ use)<smiles>COc1ccccc1</smiles><smiles>C=Cc1ccc(-c2ccc(C)cc2)cc1</smiles><smiles>c1ccc(-c2ccc(N3CCOCC3)nc2)cc1</smiles>
$74 \%$ yield
$\mathrm{X}=\mathrm{I}$ $X=1$
$\left(4^{\text {th }}\right.$ use $)$<smiles>N#Cc1ccc(-c2ccccc2)cc1</smiles><smiles>CCC(=O)c1ccc(-c2ccccc2)cc1</smiles>

Significance: Polymer-supported siloxanes were developed as transfer agents for cross-coupling reactions involving organolithium reagents. For example, the polystyrene-supported siloxane $\mathbf{1}$ was treated with an aryl or alkenyl lithium 2, and the resulting material was treated with an aryl halide $\mathbf{3}$ in the presence of $\mathrm{PdCl}_{2}$, Cul, and ligand $\mathbf{L}$ to give the corresponding product 4 in 68-97\% yield.
Comment: The transfer agent 1 was recovered almost quantitatively by simple filtration and rinsing, and reused in the cross-coupling several times. No cross-contamination of the products 4 was detected in a series of ten reactions with recycled $\mathbf{1}$ and various combinations of organolithium reagents 2 and aryl halides $\mathbf{3}$. 